\title{
Effects of low-molecular-weight chitosan on the growth performance, intestinal morphology, barrier function, cytokine expression and antioxidant system of weaned piglets
}

\author{
Shenglan $\mathrm{Hu}^{1+}$, Yu Wang ${ }^{2 \dagger}$, Xiaolu Wen ${ }^{1}$, Li Wang ${ }^{1}$, Zongyong Jiang ${ }^{1}$ and Chuntian Zheng ${ }^{1 *}$
}

\begin{abstract}
Background: Chitosan was used as an alternative to promote the growth of weaned piglets. And low-molecularweight chitosan $(\mathrm{LC})$ is one of chitosan derivatives and maintain beneficial biological properties of chitoson. The present experiment was carried out to examine the effects of LC on the growth performance, intestinal morphology, barrier function, cytokine expression, and antioxidant system of weaned piglets.

Results: A total of 40 piglets weaned at $21 \mathrm{~d}$ of age, with average body weight $6.37 \pm 0.08 \mathrm{~kg}$, were randomly assigned (5 pens/diet; 4 pigs/pen) to 2 treatments (a basal diet and the basal diet supplemented with $50 \mathrm{mg} / \mathrm{kg} \mathrm{LC}$ ) and were fed for $28 \mathrm{~d}$. Compared with the control group, average daily feed intake (ADFI), and the expression of intestinal barrier protein ZO-1 was increased $(P<0.05)$ when the piglets fed the diet supplemented with LC. No significant differences were found in average daily gain (ADG, $P>0.05$ ), gain-to-feed ratio (G:F, $P>0.05)$, the incidence of diarrhea $(P>0.05)$, or the antioxidant capacity $(P>0.05)$ between two groups. The expression of IL-1 $\beta$ and TNF- $a$ in jejunal mucosa were significantly decreased $(P<0.05)$ in piglets fed the LC-supplemented diet in comparison to the control.

Conclusion: The results of this study indicate that dietary supplementation with $L C$ at $50 \mathrm{mg} / \mathrm{kg}$ was effective for enhancing the growth performance in weaned piglets, improving intestinal barrier function and alleviating intestinal inflammation.
\end{abstract}

Keywords: Low-molecular-weight chitosan, Weaned piglet, Growth performance, Immune response, Intestinal barrier function

\section{Background}

Weaning is an important stage of gut development and may cause low feed intake, intestinal dysfunction and growth retardation in piglets $[1,2]$. Antibiotics have long been used to solve problems in the weaning period and

\footnotetext{
* Correspondence: zhengcht@163.com

'Shenglan Hu and Yu Wang contributed equally to this work. 'Institute of Animal Science, Guangdong Academy of Agricultural Sciences; State Key Laboratory of Livestock and Poultry Breeding; Key Laboratory of Animal Nutrition and Feed Science in South China, Ministry of Agriculture; Guangdong Public Laboratory of Animal Breeding and Nutrition; Guangdong Key Laboratory of Animal Breeding and Nutrition, \#1 Dafeng 1st Street, Wushan, Tianhe District, 510640 Guangzhou, Guangdong, People's Republic of China

Full list of author information is available at the end of the article
}

to promote the growth and health of piglets [3]. As the use of antibiotics can lead to bacterial resistance and potential antibiotic residues in animal products, thus many alternatives to antibiotics have been suggested and tested. Chitosan with the molecular weight of $1000 \mathrm{kDa}$, is the second most abundant carbohydrate polymer in nature $[4,5]$. It has been reported that chitosan has been widely used as a potential alternative to in-feed antibiotics in piglets and broiler chickens due to many beneficial biological properties of it, such as promoting the growth performance [6, 7], anti-oxidative [8] and immunity modulation [9]. However, chitosan is restricted to be used in food and biomedical applications because of its difficult solubility 
and instability [10]. Low-molecular-weight chitosan (LC, < $150 \mathrm{kDa})$ and chito-oligosaccharide (COS, $<5 \mathrm{kDa})$ are obtained from chitosan by physical, chemical or enzymatic methods, and have much higher solubility and stability than chitosan. Chito-oligosaccharide (COS) with the properties of antimicrobial, anti-inflammatory, anti-oxidative and immunity modulate $[11,12]$, is widely used as a dietary additive in livestock. But it is still unclear whether dietary supplementation with $\mathrm{LC}$ can affect the piglets. The objective of the present experiment, therefore, was to clarify the effects of low-molecular-weight chitosan on the growth performance, incidence of diarrhea, intestinal morphology, barrier function, immune response, and antioxidant system in weaned piglets.

\section{Methods}

\section{Ethics statements}

The piglets examined in the present study were approved by the Animal Care and Use Committee of the Institute of Animal Science, Guangdong Academy of Agricultural Sciences, with the approval number of GAASISA-2016-017.

\section{Animals and experimental treatments}

A total of 40 Duroc $\times$ Landrace $\times$ Yorkshire piglets weaned at $21 \mathrm{~d}$ of age were blocked by BW (average $6.37 \pm 0.08 \mathrm{~kg}$ ), and randomly assigned to 2 treatments with 4 pigs per pen and 5 replicate pens per treatment. The piglets were purchased from WanHe Nongmu Co., Ltd., Guangdong, China. These were (1) a control group $(\mathrm{CON})$ fed the basal diet, and (2) the basal diet supplemented with $50 \mathrm{mg} / \mathrm{kg}$ low-molecular-weight chitosan (LC); both were fed for $28 \mathrm{~d}$. The LC (molecular weight 20 to $30 \mathrm{kDa}$ ), which was obtained from chitosan by radiation pyrolysis technology, was offered by Jiaxing Korui Biotech Co., Ltd., Zhejiang, China. The composition and content of the treatment diets were shown in Table 1. Piglets were housed in a temperature-controlled nursery and had ad libitum access to feed and water. The body weight of piglets and amount of the feed was measured to calculate the average daily gain (ADG), average daily feed intake (ADFI), and gain-to-feed ratio (G:F). The number of pigs with diarrhea was recorded every day. Diarrhea index (\%) was calculated as $100 \times$ number of piglets that had diarrhea/total number of piglets.

\section{Sample collection}

The BW of each piglet was recorded at the end of the experiment. After $12 \mathrm{~h}$ fasting, five pigs (1 per pen) were randomly selected from each treatment and anaesthetised with pentobarbital sodium (50 mg/kg, i.v.). After sedation, serum was obtained by centrifuging at $2000 \times g$ for $10 \mathrm{~min}$ and stored at $-20{ }^{\circ} \mathrm{C}$ for subsequent measurements of activities of catalase (CAT), glutathione
Table 1 Ingredient and chemical composition of the basal diet (as-fed basis)

\begin{tabular}{lll}
\hline Ingredient (\%) & Control & LC \\
\hline Corn & 60.43 & 60.43 \\
Extruded soybean meal & 20.00 & 20.00 \\
Fish meal & 5.00 & 5.00 \\
Soybean protein concentrate & 2.00 & 2.00 \\
Whey powder & 7.50 & 7.50 \\
Soybean oil & 1.50 & 1.50 \\
L-Lysine.HCl & 0.25 & 0.25 \\
DL-Met & 0.10 & 0.10 \\
CaHPO & 1.05 & 1.05 \\
Limestone & 0.75 & 0.75 \\
50\% Choline Chloride & 0.12 & 0.12 \\
NaCl & 0.30 & 0.30 \\
Premix & 1.00 & 1.00 \\
Low-molecular-weight chitosan & 0.00 & 0.005 \\
Calculated analysis & & \\
DE, MJ/kg & 14.10 & 14.10 \\
CP (\%) & 19.55 & 19.55 \\
Lys (\%) & 1.17 & 1.17 \\
Met (\%) & 0.50 & 0.50 \\
Met+Cys (\%) & 0.74 & 0.74 \\
Thr (\%) & 0.77 & 0.77 \\
Ca (\%) & 0.86 \\
Available P (\%) & 0.68 \\
\hline Premix suppled & 0.68 \\
\hline
\end{tabular}

apremix supplied per $\mathrm{kg}$ : $11000 \mathrm{IU}$ of vitamin $\mathrm{A} ; 1100 \mathrm{IU}$ of vitamin $\mathrm{D}_{3} ; 80 \mathrm{IU}$ of vitamin $\mathrm{E} ; 2.5 \mathrm{mg}$ of vitamin $\mathrm{K}_{3} ; 17.5 \mathrm{mg}$ of vitamin $\mathrm{B} ; 20 \mathrm{mg}$ of vitamin $\mathrm{B}_{2}$; $10 \mathrm{mg}$ of vitamin $B_{6} ; 220 \mu \mathrm{g}$ of vitamin $B_{12} ; 150 \mathrm{mg}$ of nicotinamide; $1.5 \mathrm{mg}$ of D-calcium pantothenate; $1.5 \mathrm{mg}$ of folic acid; $3 \mathrm{mg}$ of biotin; $150 \mathrm{mg}$ of $\mathrm{Fe}$ $\left(\mathrm{FeSO}_{4}\right) ; 10 \mathrm{mg}$ of $\mathrm{Cu}\left(\mathrm{CuSO}_{4}\right) ; 10 \mathrm{mg}$ of $\mathrm{Mn}\left(\mathrm{MnSO}_{4}\right) ; 150 \mathrm{mg}$ of $\mathrm{Zn}(\mathrm{ZnO}) ;$ $0.2 \mathrm{mg}$ of I $\left(\mathrm{KIO}_{3}\right) ; 0.3 \mathrm{mg}$ of Se $\left(\mathrm{Na}_{2} \mathrm{SeO}_{3}\right)$ and $0.15 \mathrm{mg}$ of $\mathrm{Co}\left(\mathrm{LCO}_{4}\right)$

peroxidase (GSH-Px), and total superoxide dismutase (T-SOD), and contents of malondialdehyde (MDA) and total antioxidant capacity (T-AOC), using commercial kits (Nanjing Jiancheng Bioengineering Institute, Nanjing, China). The gastrointestinal tract was immediately removed after slaughter, washed with cold PBS. And then 2-3 cm segments of duodenum, jejunum and ileum were removed and fixed in $4 \%$ formaldehyde for histometric analysis. Mucosa was scraped from a $10-15 \mathrm{~cm}$ segment of jejunum and stored at $-80{ }^{\circ} \mathrm{C}$ for gene expression analyses.

\section{Analysis of small intestinal morphology}

The fixed intestinal segments were dehydrated and embedded using low-melt paraffin wax by routine methods. Three cross-sections $(5 \mu \mathrm{m})$ of each segment were dewaxed then stained with hematoxylin and eosin. Villus height and crypt depth of each intestinal segment were measured at $10 \times$ magnification using an image processing 
Table 2 Primer sequences for real-time PCR analysis

\begin{tabular}{|c|c|c|c|}
\hline Gene & Sequence $\left(5^{\prime} \rightarrow 3^{\prime}\right)$ & Product size (bp) & $\begin{array}{l}\text { GenBank accession } \\
\text { number }\end{array}$ \\
\hline \multirow[t]{2}{*}{$\mathrm{ZO}-1$} & CTCTTGGCTTGCTATTCG & 256 & XM_003353439.2 \\
\hline & AGTCTTCCCTGCTCTTGC & & \\
\hline \multirow[t]{2}{*}{ Occludin } & GTAGTCGGGTTCGTTTCC & 167 & NM_001163647.2 \\
\hline & GACCTGATTGCCTAGAGTGT & & \\
\hline \multirow[t]{2}{*}{$\mathbb{L L}-1 \beta$} & CTCCAGCCAGTCTTCATTGTTC & 132 & NM_214055.1 \\
\hline & TGCCTGATGCTCTTGTTCCA & & \\
\hline \multirow[t]{2}{*}{ TNF-a } & CACCACGCTCTTCTGCCTAC & 116 & X54859 \\
\hline & ACGGGCTTATCTGAGGTTTGAGACG & & \\
\hline \multirow[t]{2}{*}{$\operatorname{IL}-10$} & GGTTGCCAAGCCTTGTCAG & 202 & NM_214041 \\
\hline & AGGCACTCTTCACCTCCTC & & \\
\hline \multirow[t]{2}{*}{$T G F-\beta$} & GAAGCGCATCGAGGCCATTC & 162 & NM_214015 \\
\hline & GGCTCCGGTTCGACACTTTC & & \\
\hline \multirow[t]{2}{*}{$\beta$-actin } & CGGGACATCAAGGAGAAGC & 273 & DQ845171 \\
\hline & ACAGCACCGTGTTGGCGTAGAG & & \\
\hline
\end{tabular}

and analysis system. At least 10 well-oriented intact villi and their associated crypts were examined in each intestinal segment of each piglet. The mean villus height and crypt depth of each section were calculated per piglet and used for further analysis.

\section{Relative quantification of mRNA expression}

Total RNA from jejuna mucosa was extracted according to the manufacturer's instructions of TRIzol reagent (Invitrogen, Carlsbad, CA). The concentration of RNA was measured by NanoDrop ND-1000 (Thermo Fisher Scientific). And the integrity of RNA was checked by electrophoresis on 1\% agarose gel. After removed genomic DNA with gDNA Eraser (TaKaRa, Dalian, reverse transcription was carried out using PrimeScript ${ }^{\mathrm{Tm}} \mathrm{RT}$ reagent kit (TaKaRa, Dalian, China) followed the manufacturer's instructions. The expression levels of intestinal tight junction and cytokines were analyzed using $\mathrm{SYBR}^{\odot}$ Premix Ex $\mathrm{Taq}^{\mathrm{Tm}}$ II kit (Takara, Dalian, China) and $\mathrm{iQ}^{\mathrm{Tm}} 5$ Real Time PCR Detection System (Bio-Rad, Hercules, CA, USA). The sequences of the primers were listed in Table 2 . The $2^{-\Delta \Delta C t}$ method was used to estimate the abundance of mRNA.

\section{Statistical analysis}

All data were subjected to a t-tests using SAS (Version 8.1; SAS Inst. Inc., Cary, NC). Data are presented as means and SEM. $P$-values $<0.05$ were used to indicate statistical significance.

\section{Results}

\section{Growth performance and incidence of diarrhea}

As shown in Table 3, ADG and ADFI was increased by 22.28\% $(P=0.084)$ and $8.95 \%(P<0.05)$ in the piglets fed with dietary supplementation with low-molecular-weight chitosan (LC). No significant changes were found in G:F and rate diarrhea rate between control group and LC group.

\section{Small intestinal morphology}

No significant differences in villus height, crypt depth, or villus height:crypt depth in duodenum, jejunum and ileum were observed between $\mathrm{CON}$ and LC groups (Table 4, Fig. 1).

\section{Intestinal cytokines}

Dietary supplementation with low-molecular-weight chitosan $(\mathrm{LC})$ significantly decreased $(P<0.05)$ the expression of $I L-1 \beta$ and $T N F-\alpha$ in the jejunal mucosa of piglets in comparison to the CON group (Fig. 2a-b). There were no significant differences in the jejunal mucosal expression of TGF- $\beta$ and $I L-10$ (Fig. 2c-d).

Table 3 Effect of dietary supplementation with LC on growth performance of weaned piglets

\begin{tabular}{lllll}
\hline Variables & CON & LC & SEM & P-value \\
\hline ADG $(\mathrm{g} / \mathrm{d})$ & 177.7 & 217.3 & 10.03 & 0.084 \\
ADFI $(\mathrm{g} / \mathrm{d})$ & $297.3^{\mathrm{b}}$ & $323.9^{\mathrm{a}}$ & 9.93 & 0.013 \\
$\mathrm{G}: \mathrm{F}(\mathrm{g} / \mathrm{g})$ & 0.63 & 0.66 & 0.02 & 0.391 \\
Diarrhea rate (\%) & 26.32 & 25.97 & 1.08 & 0.882 \\
\hline
\end{tabular}

$A D G$ average daily gain, $A D F I$ average daily feed intake, $G: F$ gain-to-feed ratio, CON piglets fed the basal diet, LC piglets fed the basal diet with $50 \mathrm{mg} / \mathrm{kg} 20$ $30 \mathrm{kDa}$ chito-oligosaccharide, SEM standard error of mean

a,b Values within a row with different superscripts differ significantly at $P<0.05 . n=5$ 
Table 4 Effect of LC supplementation on morphology of the small intestine of weaned piglets

\begin{tabular}{|c|c|c|c|c|c|c|c|c|c|}
\hline \multirow[t]{2}{*}{ Group } & \multicolumn{3}{|c|}{ Villus heigh $(\mu \mathrm{m})$} & \multicolumn{3}{|c|}{ Crypt depth ( $\mu \mathrm{m})$} & \multicolumn{3}{|c|}{$\mathrm{VH}: \mathrm{CD}(\mu \mathrm{m}: \mu \mathrm{m})$} \\
\hline & Duodenal & Jejunum & Ileum & Duodenal & Jejunum & Ileum & Duodenal & Jejunum & Ileum \\
\hline $\mathrm{CON}$ & 376.0 & 375.1 & 330.8 & 337.1 & 245.2 & 182.8 & 1.16 & 1.57 & 1.88 \\
\hline LC & 424.0 & 373.8 & 330.7 & 295.9 & 218.4 & 213.1 & 1.45 & 1.71 & 1.58 \\
\hline SEM & 15.22 & 20.81 & 0.09 & 9.83 & 10.74 & 0.07 & 14.34 & 13.98 & 0.12 \\
\hline$P$-value & 0.118 & 0.351 & 0.106 & 0.952 & 0.232 & 0.380 & 0.768 & 0.349 & 0.247 \\
\hline
\end{tabular}

CON piglets fed the basal diet, LC piglets fed the basal diet with $50 \mathrm{mg} / \mathrm{kg}$ 20-30 kDa low-molecular-weight chitosan, VH:CD villus height: crypt depth, SEM standard error of mean, $n=5$

\section{Anti-oxidation indices}

The effect of LC on the activity of serum antioxidant enzymes and indices in weaned piglets are shown in Table 5. While there were no significant differences, activities of antioxidant enzymes, T-AOC, CAT, GSH-Px and T-SOD were slightly higher in the piglets fed LC-supplemented diets, and the concentration of MDA in serum was reduced.

\section{Indices of intestinal barrier function}

Compared with the piglets in control group, the relative expression of jejuna mucosa $Z O-1$ transcripts was dramatically increased $(P=0.025)$ in piglets from LC group, while no significant change was found in the expression of Occludin-1 (Fig. 3).

\section{Discussion}

Chitosan, one of the most abundant polymers in nature, is an alkaline polysaccharide with positive charges [13]. Because of its characteristics of nontoxic [14], and the biological activities, such as antimicrobial activity and anti-inflammatory $[15,16]$, chitosan is widely used as a dietary supplement in livestock industry to promote the growth [13, 17]. However, the influences of low-molecular-weight chitosan (LC) on the growth of livestock remain unknown. In the present study, the effect of dietary supplementation with $50 \mathrm{mg} / \mathrm{kg} \mathrm{LC}$ (20-30 kDa) on growth performance, incidence of diarrhea, intestinal morphology, intestinal barrier, cytokines expression and anti-oxidation indices were examined in weaned piglets. The results demonstrated that, after 4 wk. of post-weaning feeding, there were no significant differences in ADG and G:F between piglets fed the LC-containing and control diets. When compared with the piglets fed the CON diet, ADFI was significantly increased by about $9 \%$ and ADG increased $22 \%$ in the piglets fed LC. While the latter was not significant, it was of greater magnitude than the change in ADFI, suggesting that the effects of LC on nutrient metabolism might mediate part of the

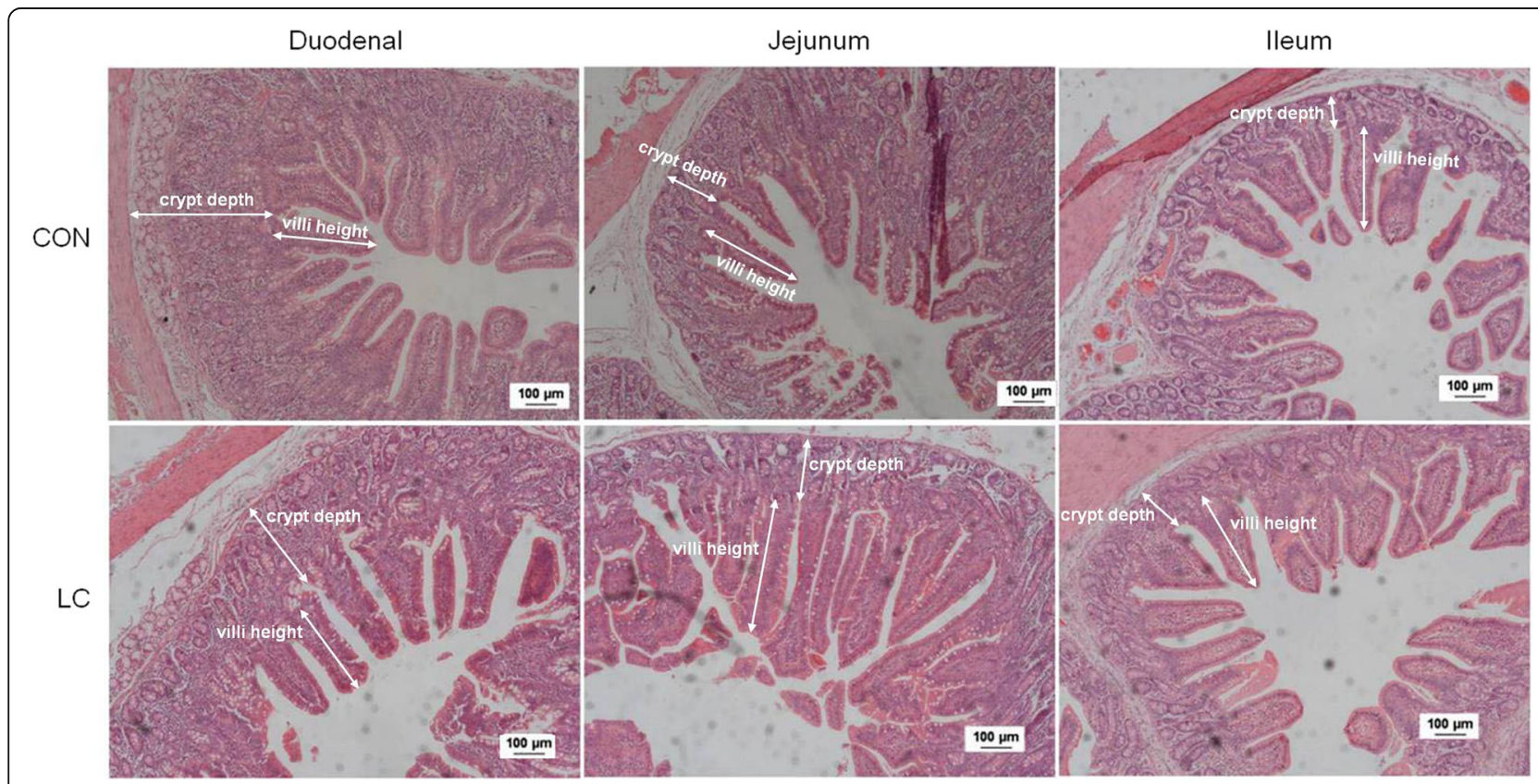

Fig. 1 Effects of LC on intestinal morphology of duodenum, jejunum and ileum. CON: piglets fed the basal diet; LC: piglets fed the basal diet with $50 \mathrm{mg} / \mathrm{kg}$ 20-30 kDa low-molecular-weight chitosan. The scale bars in each image indicate $100 \mu \mathrm{m}$ 

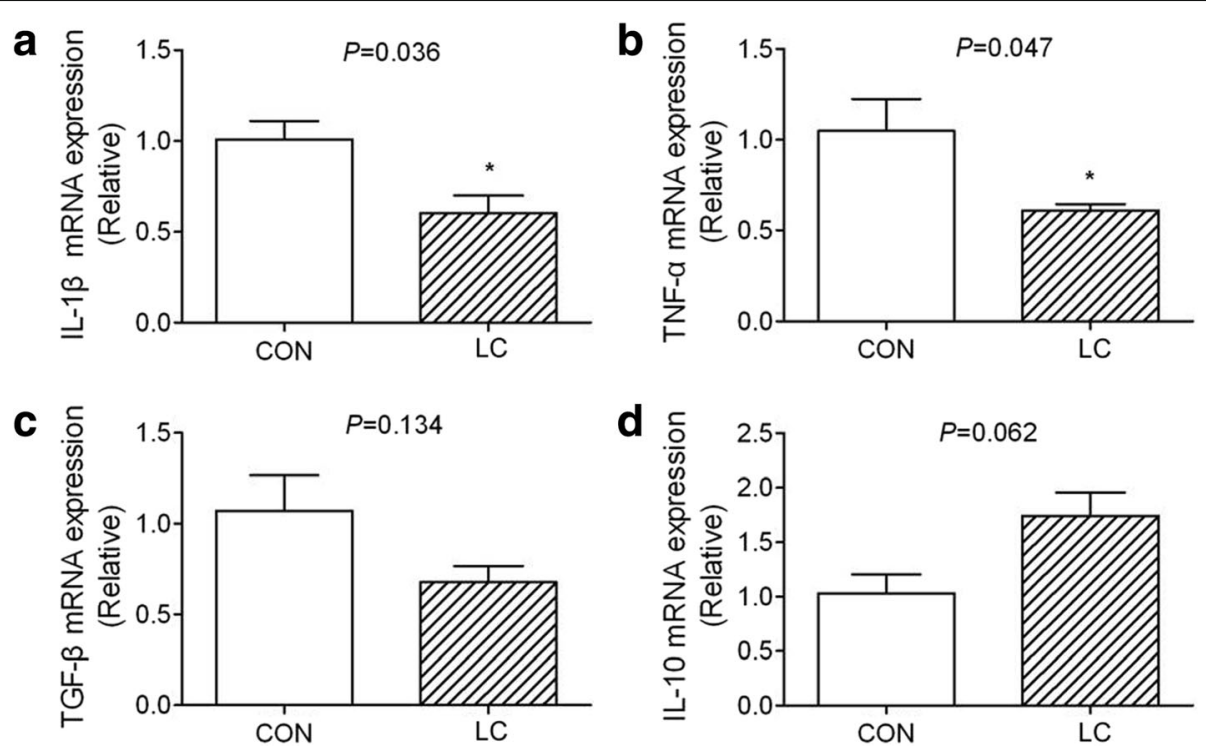

Fig. 2 The pro-inflammatory cytokine gene expression was inhibited by LC. IL-1 $\beta$ (a), TNF- $a(\mathbf{b}), T G F-\beta(\mathbf{c})$ and IL-10 (d) were quantified by RT-PCR. CON: piglets fed the basal diet; LC: piglets fed the basal diet with 50 mg/kg 20-30 kDa low-molecular-weight chitosan. Five piglets per treatment. ${ }^{*} P<0.05$

growth response. It has been demonstrated that low molecular weight chitosans prevented the increases in bodyweight by decreasing the absorption of dietary lipids [18] and intestinal disaccharidase activities [19]. Many studies showed positive effects of another small molecular weight $\mathrm{COS}$ on the growth performance of weaned pigs; other studies found that there were no significant differences between piglets fed COS-supplemented and CON diets $[20,21]$. Walsh et al. [22] demonstrated that 5 to $10 \mathrm{kDa}$ COS possessed antibacterial activity and the 10 to $50 \mathrm{kDa}$ preparation was optimum for enhancing intestinal structure. It can be speculated that the different effects of the LC on growth performance of weaned piglets may result from the molecular weight, dosage, solubility or the duration of LC supplementation.

Diarrhea in the post-weaning period is always due to intestinal dysfunction. The decrease of villus height and the

Table 5 Effect of LC supplementation on serum anti-oxidation indices of weaned piglets

\begin{tabular}{lllll}
\hline Group & CON & LC & SEM & $P$-value \\
\hline CAT $(\mathrm{U} / \mathrm{mL})$ & 101.3 & 107.3 & 7.13 & 0.704 \\
GSH-Px $(\mathrm{U} / \mathrm{mL})$ & 44.1 & 45.4 & 0.69 & 0.357 \\
T-SOD $(\mathrm{U} / \mathrm{mL})$ & 111.6 & 114.2 & 4.17 & 0.779 \\
MDA $(\mathrm{nmol} / \mathrm{mL})$ & 3.10 & 1.74 & 0.55 & 0.233 \\
T-AOC $(\mathrm{U} / \mathrm{mL})$ & 1.45 & 1.82 & 0.10 & 0.064
\end{tabular}

CON piglets fed the basal diet, $L C$ piglets fed the basal diet with $50 \mathrm{mg} / \mathrm{kg} \mathrm{20-}$ $30 \mathrm{kDa}$ low-molecular-weight chitosan, CAT activities of catalase, GSH-Px glutathione peroxidase, $T$-SOD total superoxide dismutase, MDA contents of malondialdehyde, $T-A O C$ total antioxidant capacity, SEM standard error of mean, $\mathrm{n}=5$ increase of crypt depth associated with dysfunction have been found in previous studies [23-25]. Liu et al. [20] observed that $160 \mathrm{mg} / \mathrm{kg}$ supplemental COS reduced the incidence of diarrhea and increased the villus:crypt ratio in weaned piglets challenged with Escherichia coli. Supplementation with 200,400, or $600 \mathrm{mg} / \mathrm{kg}$ COS in diets of weaned piglets not influencing the villus:crypt ratio in duodenum, jejunum, or ileum [7]. In the results of the present experiment, basic dietary-supplemented with LC at $50 \mathrm{mg} / \mathrm{kg}$ did not influence incidence of diarrhea, villus height, crypt depth and villus:crypt ratio in the duodenum, jejunum and ileum. Supplementation with $\mathrm{LC}$ at $50 \mathrm{mg} /$ $\mathrm{kg}$ tended to increase the villus:crypt ratio in duodenum and jejunum of the piglets. Tight junctions are the important determinants of epithelial barrier functions [26]. When the piglets feed with $30 \mathrm{mg} / \mathrm{kg}$ COS, the expression of epithelial tight junction, such as occluding- 1 and $\mathrm{ZO}-1$ was decreased [21]. The present study found that the jejuna mucosa expression of ZO-1 was significantly enhanced by $50 \mathrm{mg} / \mathrm{kg}$ dietary LC $(20-30 \mathrm{kDa})$, thought it did not affect the incidence of diarrhea in weaned piglets. Further researches were needed to be carried out to explore the effects of low dosage of COS on intestinal barrier function.

The balance between pro-inflammatory and anti-inflammatory cytokines is of great importance for the health of weaned piglets [27]. It has been reported that the intestinal expression of pro-inflammatory cytokine genes, such as $I L-1 \beta, I L-6$, and $T N F-\alpha$, is up-regulated in weaned piglets [28] and the present study found that dietary supplementation with $50 \mathrm{mg} / \mathrm{kg} \mathrm{LC}(20-30 \mathrm{kDa})$ significantly 
ZO-1

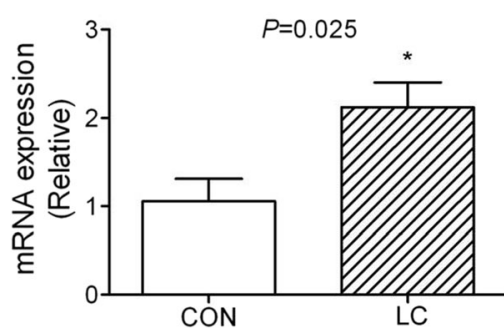

Occludin-1

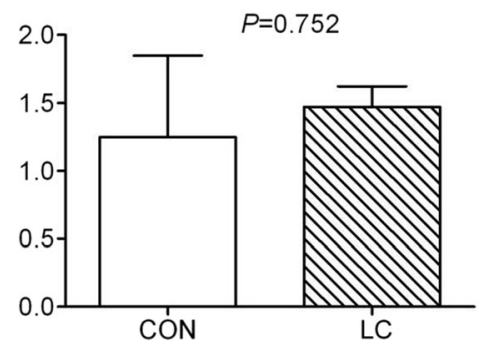

Fig. 3 Effect of dietary LC on jejunal expression of intestinal barrier genes. CON: piglets fed the basal diet; LC: piglets fed the basal diet with $50 \mathrm{mg} / \mathrm{kg}$ 20-30 kDa low-molecular-weight chitosan. Five piglets per treatment. ${ }^{*} P<0.05$

reduced the jejunal mucosal expression of pro-inflammatory cytokines $I L-1 \beta$ and $T N F-\alpha$ while not influencing that of anti-inflammatory cytokines $I L-10$ and TGF- $\beta$. The data suggest that dietary supplementation with $50 \mathrm{mg} / \mathrm{kg} \mathrm{LC}$ modulated immune responsivity by inhibiting the expression of pro-inflammatory cytokines in weaned piglets.

Oxidative stress accompanies weaning and plays a very important role in intestinal health [29]. The present study found that dietary supplementation with $50 \mathrm{mg} / \mathrm{kg}$ LC tended to increase the concentration of the total anti-oxidant capacity and decrease the concentration of MDA in serum, while all the indices showed no significant difference. Previous study reported that dietary supplementation with $30 \mathrm{mg} / \mathrm{kg}$ COS had dramatically inhibited T-AOC and T-SOD [21]. In contrast, no significant differences in the antioxidant enzymes and MDA were observed here in piglets supplemented with $50 \mathrm{mg} / \mathrm{kg} \mathrm{LC}$. It is widely known that diarrhea usually activates the antioxidant system [30], so the very slight changes in activities of antioxidant enzyme and the concentration of MDA were consistent with the incidence of diarrhea compared the control and LC-groups.

\section{Conclusions}

These observations suggested that $50 \mathrm{mg} / \mathrm{kg}$ low-mole cular-weight chitosan (LC) supplements enhanced the growth of weaned piglets, improved intestinal barrier and inhibited intestinal inflammation. The findings will contribute to the guidance on LC supplements.

\section{Abbreviations}

ADFI: Average daily feed intake; ADG: Average daily gain; BW: Body weight; CAT: Activities of catalase; CON: Control; COS: Chito-oligosaccharide; G:F: Gain-to-feed ratio; GSH-Px: Glutathione peroxidase; LC: Low-molecularweight chitosan; MDA: Contents of malondialdehyde; T-AOC: Total antioxidant capacity; T-SOD: total superoxide dismutase

\section{Acknowledgments}

We would like to thank W. B. Currie, Emeritus Professor, Cornell University, Ithaca, NY for suggestions on the manuscript.

\section{Authors' contribution}

SH and YW helped in experiment studies, interpretation of data and preparation of the manuscript. XW, LW and ZJ helped in statistical analysis and manuscript revision. $\mathrm{CZ}$ designed the experiment and overall coordinated the project. All authors read and approved the final manuscript.

\section{Funding}

The design of this work, samples collection and analysis were supported by National Natural Science Foundation of China (No. 31601955), the Start-up Fund of the Natural Science Foundation of Guangdong Province (No. 2016A030310322), National Science and Technology Support Program (2012BAD39B01-5) and China Agriculture Research System (CARS-35). The interpretation of data, the modification of manuscript was get the financial support by Science and Technology Planning Project of Guangzhou (201607020035), Science and Technology Program of Guangdong Province (2016A020210041) and Tianjin Science Technology Program (15ZXZYNC00100, ITTPRS2017006).

\section{Availability of data and materials}

The datasets generated during and/or analysed during the current study are available from the corresponding author on reasonable request.

\section{Ethics approval and consent to participate}

The experimental design were approved by Animal Care and Use Committee of the Institute of Animal Science, Guangdong Academy of Agricultural Sciences (Permit Number: GAASISA-2016-017). The collection of specimens in this work was strictly complied the approved guidelines and regulations of Animal Care and Use Committee.

\section{Consent for publication}

Not applicable.

\section{Competing interests}

The authors declare that they have no competing interests.

\section{Publisher's Note}

Springer Nature remains neutral with regard to jurisdictional claims in published maps and institutional affiliations.

\section{Author details}

'Institute of Animal Science, Guangdong Academy of Agricultural Sciences: State Key Laboratory of Livestock and Poultry Breeding; Key Laboratory of Animal Nutrition and Feed Science in South China, Ministry of Agriculture; Guangdong Public Laboratory of Animal Breeding and Nutrition; Guangdong Key Laboratory of Animal Breeding and Nutrition, \#1 Dafeng 1st Street, Wushan, Tianhe District, 510640 Guangzhou, Guangdong, People's Republic of China. ${ }^{2}$ Hebei depond animal health care science and technology co., Ltd, \#8 shuangtong Road, Mengtong, Luquan District, 050204 Shijiazhuang, Hebei, People's Republic of China. 
Received: 22 February 2018 Accepted: 24 June 2018

Published online: 04 July 2018

\section{References}

1. Kang $P$, Wang $M$, Hou YQ, Yin YL, Ding BY, Zhu HL, et al. Effects of oral administration of spermine on the development of small intestine and growth performance of weaned pigs. J Anim Vet Adv. 2012;11(15):2782-7.

2. Lalles JP, Bosi P, Smidt H, Stokes CR. Nutritional management of gut health in pigs around weaning. Proc Nutr Soc. 2007:66(2):260-8.

3. Gong J, Yin F, Hou Y, Yin Y. Review: chinese herbs as alternatives to antibiotics in feed for swine and poultry production: potential and challenges in application. Can J Anim Sci. 2014;94(2):223-41.

4. Knaul JZ, Hudson SM, Creber KA. Crosslinking of chitosan fibers with dialdehydes: proposal of a new reaction mechanism. J Polym Sci Pol Phys. 1999;37(11):1079-94.

5. Kim S, Rajapakse N. Enzymatic production and biological activities of chitosan oligosaccharides (COS): a review. Carbohyd Polym. 2005;62(4):357-68.

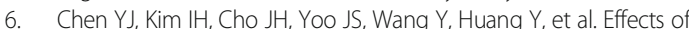
chitooligosaccharide supplementation on growth performance, nutrient digestibility, blood characteristics and immune responses after lipopolysaccharide challenge in weanling pigs. Livest Sci. 2009;124(1-3):255-60

7. Yang CM, Ferket PR, Hong QH, Zhou J, Cao GT, Zhou L, et al. Effect of chitooligosaccharide on growth performance, intestinal barrier function, intestinal morphology and cecal microflora in weaned pigs. J Anim Sci. 2012;90(8):2671-6.

8. Anandan R, Ganesan B, Obulesu T, Mathew S, Kumar RS, Lakshmanan PT, et al. Dietary chitosan supplementation attenuates isoprenaline-induced oxidative stress in ratmyocardium. Int J Biol Macromol. 2012;51(5):783-7.

9. Kobayashi S, Terashima $Y$, Itoh $\mathrm{H}$. Effects of dietary chitosan on fat deposition and lipase activity in digesta in broiler chickens. Br Poult Sci. 2002:43(2):270-3.

10. Hemantaranjan AA. Future perspective in crop protection: chitosan and its oligosaccharides. Adv Plants Agric Res. 2014;1(1):00006.

11. Holappa J, Hjalmarsdottir M, Masson M, Runarsson OV, Asplund T, Soininen $\mathrm{P}$, et al. Antimicrobial activity of chitosan N-betainates. Carbohyd Polym. 2006;65(1):114-8.

12. Swiatkiewicz S, Swiatkiewicz M, Arczewskawlosek A, Jozefiak D. Chitosan and its oligosaccharide derivatives (chito-oligosaccharides) as feed supplements in poultry and swine nutrition. J Anim Physiol Anim Nutr (Berl). 2015;99(1):1-12.

13. Li LL, Wu X, Peng HZ, Fan MZ, Kong XF, Yin YL, et al. The effect of dietary addition of a polysaccharide from Atractylodes macrophala Koidz on growth performance, immunoglobulin concentration and IL-1 $\beta$ expression in weaned piglets. J Agr Sci. 2009;147(5):625-31.

14. Goiri I, Oregui LM, Garcia-Rodriguez A. Use of chitosans to modulate ruminal fermentation of a 50:50 forage-to-concentrate diet in sheep. J Anim Sci. 2010;88(2):749-55.

15. Benhabiles MS, Salah R, Lounici H, Drouiche N, Goosen MF, Mameri N. Antibacterial activity of chitin, chitosan and its oligomers prepared from shrimp shell waste. Food Hydrocoll. 2012;29(1):48-56.

16. Dai T, Tegos GP, Burkatovskaya M, Castano AP, Hamblin MR. Chitosan acetate bandage as a topical antimicrobial dressing for infected burns. Antimicrob Agents Chemother. 2009;53(2):393-400.

17. Xiao DF, Wang YF, Liu G, He JH, Qiu W, Hu XG, et al. Effects of chitosan on intestinal inflammation in weaned pigs challenged by enterotoxigenic Escherichia coli. PLoS One. 2014;9(8):e104192.

18. Sumiyoshi M, Kimura Y. Low molecular weight chitosan inhibits obesity induced by feeding a high-fat diet long-term in mice. J Pharm Pharmacol. 2006;58(2):201-7.

19. Chiu CY, Feng SA, Liu SH, Chiang MT. Functional comparison for lipid metabolism and intestinal and fecal microflora enzyme activities between low molecular weight chitosan and chitosan oligosaccharide in high-fatdiet-fed rats. Mar Drugs. 2017;15(7):E234. https://doi.org/10.3390/ md15070234.

20. Liu P, Piao XS, Kim SW, Wang LX, Shen YB, Lee HS, et al. Effects of chitooligosaccharide supplementation on the growth performance, nutrient digestibility, intestinal morphology, and fecal shedding of Escherichia coli and lactobacillus in weaning pigs. J Anim Sci. 2008;86(10):2609-18.

21. Xiong X, Yang HG, Wang XC, Hu Q, Liu CX, Wu X, et al. Effect of low dosage of chito-oligosaccharide supplementation on intestinal morphology, immune response, antioxidant capacity, and barrier function in weaned piglets. J Anim Sci. 2015:93(3):1089-97.

22. Walsh AM, Sweeney T, Bahar B, Flynn B, O'Doherty JV. The effect of chitooligosaccharide supplementation on intestinal morphology, selected microbial populations, volatile fatty acid concentrations and immune gene expression in the weaned pig. Animal. 2012;6(10):1620-6.

23. Montagne L, Boudry G, Favier C, Le Huërou-Luron I, Lallès JP, Sève B. Main intestinal markers associated with the changes in gut architecture and function in piglets after weaning. Brit J Nutr Br J Nutr. 2007;97(1):45-57.

24. Verdonk JM, Bruininx EM, Meulen JV, Verstegen MW. Post-weaning feed intake level modulates gut morphology but not gut permeability in weaned piglets. Livest Sci. 2007;108(1):146-9.

25. $\mathrm{Hu} \mathrm{CH}$, Xiao K, Luan ZS, Song J. Early weaning increases intestinal permeability, alters expression of cytokine and tight junction proteins, and activates mitogen-activated protein kinases in pigs. J Anim Sci. 2013;91(3):1094-101.

26. Ren W, Yin J, Wu M, Liu G, Yang G, et al. Serum amino acids profile and the beneficial effects of L-arginine or L-glutamine supplementation in dextran sulfate sodium colitis. PLoS One. 2014;9(2):e88335.

27. Ren W, Zou L, Li N, Wang Y, Liu G, Peng Y, et al. Dietary arginine supplementation enhances immune responses to inactivated pasteurella multocida vaccination in mice. Br J Nutr. 2013:109(5):867-72.

28. Pié S, Lallès JP, Blazy F, Laffitte J, Sève B, Oswald IP. Weaning is associated with an upregulation of expression of inflammatory cytokines in the intestine of piglets. J Nutr. 2004;134(3):641-7.

29. Wang J, Chen L, Li P, Li X, Zhou H, Wang F, et al. Gene expression is altered in piglet small intestine by weaning and dietary glutamine supplementation. J Nutr. 2008;138(6):1025-32.

30. Granot E, Kohen R. Oxidative stress in childhood-in health and disease states. Clin Nutr. 2004;23(1):3-11.

\section{Ready to submit your research? Choose BMC and benefit from:}

- fast, convenient online submission

- thorough peer review by experienced researchers in your field

- rapid publication on acceptance

- support for research data, including large and complex data types

- gold Open Access which fosters wider collaboration and increased citations

- maximum visibility for your research: over $100 \mathrm{M}$ website views per year

At BMC, research is always in progress.

Learn more biomedcentral.com/submissions 